\title{
AS NOVAS TECNOLOGIAS REPRODUTIVAS CONCEPTIVAS NO FEMINISMO
}

\section{Vera Simone Schaefer Kalsing ${ }^{1}$}

Resumo: Neste artigo, discuto as contribuições de algumas autoras feministas contemporâneas para o debate que envolve questões éticas, políticas, religiosas, econômicas, culturais, de gênero e de etnia que permeiam o desenvolvimento e a aplicação das Novas Tecnologias Reprodutivas conceptivas (NTRc) nas sociedades capitalistas contemporâneas, sobretudo no que diz respeito ao Brasil. Grande parte das teóricas feministas entende o desenvolvimento das NTRc e sua aplicação como uma questão que deva ser discutida, principalmente, considerando o contexto dos países pobres ou em desenvolvimento, como o Brasil. Algumas visões feministas são, inclusive, bastante críticas dessas tecnologias.

Palavras chave: gênero; tecnologias reprodutivas conceptivas.

Abstract: In this article, I discuss the contributions of some contemporary feminist authors to the debate that involves ethical, political, religious, economic, cultural, gender and ethnic issues that permeate the development and application of New Conceptual Reproductive Technologies (NTRc) in capitalist societies contemporary, especially with regard to Brazil. Most of the feminist theorists understand the development of NTRc and its application as an issue that should be discussed, especially considering the context of poor or developing countries, such as Brazil. Some feminist views are even quite critical of these technologies.

Keywords: gender; conceptual reproductive technologies.

Neste artigo, discuto as contribuições de algumas autoras feministas contemporâneas para o debate que envolve questões éticas, políticas, religiosas, econômicas, culturais, de gênero e de etnia que permeiam o desenvolvimento e a aplicação das Novas Tecnologias Reprodutivas conceptivas (NTRc) ${ }^{2}$ nas sociedades capitalistas contemporâneas, sobretudo no que diz respeito ao Brasil.

Grande parte das teóricas feministas entende o desenvolvimento das NTRc e sua aplicação como uma questão que deva ser discutida, principalmente, considerando o contexto dos países pobres ou em desenvolvimento, como o Brasil.

Mestre e Doutora em Sociologia pela Universidade Federal do Rio Grande do Sul. Professora Adjunta do Departamento de Ciências Humanas da Universidade Federal de Lavras. E-mail: vera.kalsing@gmail.com.

$2 \quad$ As Novas Tecnologias Reprodutivas conceptivas podem também ser chamadas de Reprodução Humana Assistida (RHA), Reprodução Medicamente Assistida (RMA) e Novas Tecnologias Reprodutivas Conceptivas e Genéticas (NTRc e Genéticas). Atualmente, já existe entre os/as especialistas no assunto uma diferenciação entre as Novas 
Algumas visões feministas são, inclusive, bastante críticas dessas tecnologias.

Com o advento das NTRc, por um lado, as mulheres ganharam mais autonomia, considerando as possibilidades de uma gravidez tardia ou da minimização dos efeitos da idade sobre seu material genético por meio do congelamento de óvulos e/ou embriões (BARBOSA, 2000), ou ainda da opção pela maternidade sem um parceiro ou em uma relação homoafetiva, etc. Por outro, elas podem sofrer a pressão social para procriar, já que, segundo Rohden (2003), com as NTRc, a possibilidade do acesso à maternidade é facilitado, (embora não garantido, e ainda assim, muito mais a uma determinada classe social, já que depende de recursos financeiros), o que, de certa forma, vem reforçar a maternidade como um imperativo.

De acordo com Laborie (1993), de uma ótica feminista, o que está em jogo nas NTR é o fato de terem reposto o debate sobre o lugar e o papel das mulheres na gestão social da reprodução e reacenderem a questão da diferença sexual.

Conforme a autora, para algumas teóricas do feminismo, as Novas Tecnologias da Reprodução podem representar uma forma de combater o patriarcado.

As descobertas científicas que tornam potencialmente evitável a associação entre o corpo das mulheres e a reprodução - que é uma das bases da sua opressão no sistema patriarcal - podem constituir, se soubermos bem utilizá-las, fatores importantes de luta contra esse sistema (PEYRET; WIELS apud LABORIE, 1993, p. 447).

Para outras, no entanto, as NTR podem significar uma forma de colocar as mulheres à mercê das experiências científicas, quando não se sabe ainda todas as consequências que essas tecnologias podem trazer à sua saúde. Como, por exemplo, nos casos de mulheres que tenham sido expostas a uma ou várias estimulações hormonais, em doses tão elevadas quanto as que são utilizadas na fertilização in vitro, e que possam vir a desenvolver certos tipos de câncer (BELAISCH-ALLART apud LABORIE, 1993).

Já nos anos 1970, as teóricas do patriarcado entendiam que a reprodução era a "amarga armadilha" das mulheres e a sua libertação viria das transformações na tecnologia da reprodução que poderia, num futuro não demasiadamente longínquo, eliminar a necessidade dos corpos das mulheres como agentes da reprodução da espécie (SCOTT, 1995). ${ }^{3}$

Para Rotania (2001), a utopia desenhada por Firestone na década de 1970 
(biotecnologia humana e cibernética) finalmente estaria em vias de realização, tendo a humanidade atingido um estágio no qual a mudança das relações sociais de gênero pode corresponder a mudanças tecnológicas operadas na própria essência material da capacidade reprodutiva de homens e mulheres.

Resta saber se esta mudança inédita, que provoca encantamentos em muitos, re-
ceio em poucos e, finalmente, espanto em outros, confere efetivo poder às mulhe-
res ou indica outra dimensão das relações sociais de sexo ainda de natureza nebu-
losa e, devido a isto, de complexa interpretação. (ROTANIA, 2001, p. 377-378).

No entendimento de Barbosa (2000), as NTRc vêm reforçar a visão da reprodução como função inerente da mulher, como uma característica determinante de seu ser, prejudicando os avanços sociais conseguidos por meio de um longo processo de questionamento da relação mulher-natureza.

Para algumas feministas, no contexto das NTRc, o problema fundamental continua o mesmo: o lugar da produção e da reprodução na sociedade, bem como o reconhecimento da respectiva contribuição de homens e mulheres no conjunto desse trabalho social (TAIN, 2005).

Stolcke (1998) chama a atenção para o lugar da mulher como produtora e disponibilizadora de óvulos e úteros, necessários à atual medicina da reprodução. A autora interroga-se sobre as diferenças sexuais na procriação e por possiveis alterações nas noções vigentes de concepção que uma técnica como a clonagem poderia acarretar. $O$ que se percebe, de fato, até o momento, segundo Corrêa (1998), é um aprofundamento da apropriação do corpo feminino por parte da pesquisa biomédica no campo da reprodução e, nas palavras de Stolcke, um "reforço da maternidade como destino e responsabilidade da mulher" (STOLCKE apud CORRÊA, 1998, p. 135), ainda que as novas tecnologias conceptivas e contraceptivas tenham oferecido às mulheres, ao menos nos países ricos, maior liberdade para decidir sobre seus corpos (STOLCKE, 1998).

Los contraceptivos han disociado el sexo de la procreación y nos permitem mayor libertad para gestionar nuestras facultades procreativas. Las nuevas tecnologías conceptivas han translocado las tradicionales nociones de filiación. El más reciente giro biotecnológico acentúa las diferencias de sexo. Las nuevas técnicas reproductivas convierten los úteros y los ovocitos en el bien más preciado y precioso y los disocian de las personas a que pertenecen. (STOLCKE, 1998, p. 152-153).

Para as feministas, o controle médico da reprodução diminui o controle das mulheres sobre seus corpos. "A tecnologia reprodutiva, ao substituir algumas das funções corporais, desloca o lugar central das mulheres no processo reprodutivo 
e sua capacidade de agenciamento" (RAMÍREZ, 2003a, p. 155).

As NTR significaram um salto qualitativo no controle médico-técnico da procriação humana, considerando que seus objetos privilegiados são as mulheres, na medida em que, devido às diferenças fisiológicas reprodutivas, isto é, as diferenças de sexo, essas tecnologias requerem acima de tudo a manipulação do corpo feminino (STOLCKE, 1998).

Da mesma maneira, para Scavone (2004, p. 69 e 70):

As práticas destas tecnologias trazem à tona o debate de fundo da ética e da ciência, dos ganhos e perdas das conquistas tecnológicas, da noção de progresso e de desenvolvimento humano e, sobretudo, das relações de gênero que lhes permeiam. Isto porque, além de estarem relacionadas com políticas demográficas controlistas ou natalistas, elas têm a particularidade de afetar a vida privada de cada um/a de nós, interferindo diretamente no corpo em seus aspectos mais íntimos: a vivência da sexualidade e a reprodução da vida. Esta interferência que, via de regra, acontece no corpo feminino, diminui o controle das mulheres sobre seus corpos, dando lugar ao controle médico e científico dos mesmos.

Para essa autora, as tecnologias reprodutivas são direcionadas quase exclusivamente para as mulheres, embora a sua produção, difusão e controle estejam majoritariamente com os homens. Esta constatação evidencia que as relações de gênero, na vivência da sexualidade e da reprodução, estão marcadas pela prática desigual das tecnologias reprodutivas: as mulheres continuam assumindo as questões reprodutivas, vivendo antigos conflitos na decisão da maternidade, apesar das inúmeras técnicas oferecidas no mercado.

A busca pela realização da maternidade (e/ou da parentalidade) não se faz sem conflitos: desde a decisão de querer ou não querer filhos/as até assumir os efeitos secundários na saúde pelo uso das tecnologias reprodutivas disponiveis, as mulheres percorrem uma trajetória que lhes impõe o clássico dilema: vida familiar $x$ vida profissional e continuam sendo as principais artífices deste processo (SCAVONE, 2004).

De acordo com Giddens (apud SCAVONE, 2004), o processo de globalização econômica torna o consumo de todos os tipos de tecnologias cada vez mais generalizado e próximo de cada um/a de nós. Ele provoca a transformação nos contextos da experiência social, atingindo a vida privada das pessoas, influenciando comportamentos.

Com a expansão das tecnologias reprodutivas, a experiência da maternidade (em alguns casos, da paternidade) muitas vezes está sendo mediada pelas técnicas disponíveis que, por sua vez, são arbitradas pela medicina e pela ciência em geral (SCAVONE, 2004). 
Neste processo, está embutida a lógica de adesão à modernidade, que se desdobra em inúmeras consequências na vida quotidiana. Implica, entre outras coisas, diminuir o número dos filhos/as, mas também continuar a tê-los/as; solucionar problemas ligados a projetos de vida, a desejos profundos e ao próprio corpo, corpo este que é objeto por excelência destas tecnologias. Implica, em última instância, ceder à lógica do tempo industrial, da eficácia, dos resultados imediatos. (SCAVONE, 2004, p. 85).

Todavia, conforme Scavone (2004), no Brasil, essa adesão é permeada pelas profundas desigualdades sociais existentes no país, expressas, neste caso, no acesso desigual aos serviços de saúde e às tecnologias de ponta. A ampliação da oferta cria a ilusão de que é possivel escolher, aumentando os conflitos e a responsabilidade das mulheres no que tange à reprodução. Além disso, essa livre oferta esbarra nas desigualdades sociais existentes no pais, que limitam a autonomia dos indivíduos.

Para essa autora, a experiência das técnicas reprodutivas sugere a difusão e imposição do modelo médico científico, mas também pressupõe a busca (ou a recusa) que mulheres e homens, em diferentes situações, fazem desse modelo. A dominação da natureza, no caso da reprodução, pode ser considerada como um elemento de autonomia para as mulheres, mas, ao mesmo tempo, pode representar um elemento de controle político da natalidade, ou ainda um fator de risco para a saúde.

Em se tratando de Brasil, os estudos (BARBOSA, 2000) ressaltam a importância da consideração dos aspectos econômicos quando se fala em acesso às NTR, tendo em vista a precariedade da assistência à saúde, principalmente a saúde reprodutiva das mulheres.

Scavone (2004) chama a atenção para o fato de que as NTRc trazem à tona as diferenças de classe existentes no país, ressaltando as contradições do consumo das tecnologias reprodutivas na sociedade brasileira: de um lado, elas possibilitam às mulheres a livre escolha da maternidade e uma maior autonomia individual; de outro, elas têm consequências para a saúde das mulheres que são minimizadas por razões econômicas, sociais, políticas, demográficas e subjetivas. Razões que, por sua vez, estimulam o uso dessas tecnologias.

Os limites da autonomia individual na escolha das tecnologias reprodutivas são dados pelas próprias desigualdades sociais e sexuais que refletem a exclusão social e a dominação masculina: os métodos pesados, considerados mais eficazes, são oferecidos como panaceia dos males socioeconômicos às camadas desprovidas da população, atingindo o corpo e a saúde das mulheres. (SCAVONE, 2004, p. 87). 
As novas tecnologias reprodutivas também têm sido criticadas por algumas feministas como um princípio fundamental de não se aceitar a construção da vida humana de maneira artificial, o que traz consigo, nesta maneira de ver, o receio de usos e práticas eugênicas (ÁVILA, 1993).

No parágrafo 249 da Plataforma Política Feminista da Conferência Nacional de Mulheres, realizada em 2002 em Brasilia, está referendado:

As novas tecnologias reprodutivas têm seu acesso restrito a quem possa pagar por elas. Não são regulamentadas em lei, o que favorece a criação de um verdadeiro mercado, sem controle e acompanhamento e o uso de muitas mulheres e homens como cobaias de pesquisas. As novas tecnologias reprodutivas conceptivas ainda contêm processos inseguros e experimentais; logo, a sua biossegurança precisa ser garantida para o seu pleno exercício. (OLIVEIRA, 2002, p. 5).

Do ponto de vista social, há uma grande diferença entre a invenção dos métodos contraceptivos e o surgimento das Novas Tecnologias da Reprodução. Se os primeiros correspondiam a uma demanda das mulheres, as NTR resultam de uma oferta médica e científica. $O$ que resta saber é se as mulheres podem encontrar nessa "oferta" meios através dos quais possam exercer suas escolhas, satisfazer seus interesses (LABORIE, 1993).

Stolcke (apud COSTA, 2003) considera que as novas tecnologias reprodutivas acabam por reforçar as desigualdades entre homens e mulheres, enfatizando o desejo dos homens de ter filhos biologicamente seus, por meio da manipulação do corpo feminino, pois, na sociedade de classes ocidental:

um conceito de status social, em última instância, determinado pelos próprios genes, sublinha um entendimento biológico individualizado da paternidade/maternidade que resulta, por sua vez, na obsessão com ter uma "criança propriamente sua" se necessário através de fertilização in vitro. Por causa dessa naturalização da paternidade/maternidade em uma sociedade desigual, mulheres estão sujeitas ao controle dos homens sobre sua capacidade reprodutiva. Uma variante moderna é a maternidade tecnológica a serviço da solicitação dos homens da paternidade biológica. (STOLCKE apud COSTA, 2003, p. 77, grifo da autora).

No entanto, é preciso considerar da mesma forma o desejo de algumas muIheres de terem filhos biológicos. Estudos (TAMANINI, 2003) apontam para o fato de que muitas mulheres desejam passar pela experiência da gravidez, para terem, se possivel, filhos biologicamente seus ou mesmo com material genético doado por outras mulheres. $O$ que se destaca, neste caso, é a importância da gestação para certas mulheres, em função da naturalização deste papel social. 
No contexto de expansão e desenvolvimento da RA, percebe-se a construção da naturalidade do desejo do filho biológico e o revigoramento da família consanguínea como valor. E essa "naturalidade do desejo" de ter filhos "geneticamente aparentados e sadios" transformou-se na principal justificativa para o desenvolvimento acelerado das tecnologias reprodutivas, cada vez mais sofisticadas e invasivas, considerando que a frustração desse desejo seria motivo de sofrimento para mulheres e homens que não podem conceber espontaneamente (RAMÍREZ, 2003a).

\begin{abstract}
A invenção científica adquire sentido em sua capacidade de reinventar o social em função de valores que, no caso da RA, estão associados a fertilidade, gênero, maternidade, hereditariedade, reprodução consanguínea, parentesco, etc. Valores nos quais adquire relevância o desejo do filho biológico, tido como a principal justificativa para o desenvolvimento e oferta de serviços de RA. (CORRÊA apud RAMÍREZ, 2003a, p. 4).
\end{abstract}

Segundo Ramírez (2003b), a possibilidade tecnológica de habilitar as pessoas para terem filhos do "próprio sangue" traz consigo um cenário no qual a adoção de crianças é desvalorizada. Essa antiga solução social para resolver a ausência de filhos continua existindo, porém, conforme a autora, como o último recurso, após sucessivas e diferentes tentativas de recorrer às várias técnicas reprodutivas disponiveis.

\begin{abstract}
O status conferido a cada uma dessas formas (biológica e social) de contornar a infertilidade é bastante diferente. A adoção de crianças é um fenômeno oculto nessa discussão, ignorado na maioria das pesquisas desenvolvidas no país sobre reprodução assistida. Do mesmo modo que as análises omitem a adoção como solução disponivel, também os profissionais da reprodução assistida a ignoram como alternativa desejável para as pessoas ou casais sem filhos. (RAMÍREZ, 2003b, p. 115).
\end{abstract}

$E$, dentro desse contexto, de revigoramento da família consanguínea como valor, de construção do desejo do filho biológico, a maternidade é reforçada como um imperativo, é vista como função inerente a uma suposta "natureza feminina".

Há também o que algumas autoras chamam de "construção da infertilidade" (PINOS, 2003). Questiona-se até que ponto a técnica surge para solucionar problemas de infertilidade ou se a própria técnica que criaria a infertilidade.

Por que um número tão grande de mulheres se sente infértil? Claro que a infertilidade sempre existiu, mas, provavelmente está mais em evidência graças ao progresso da ciência e da tecnologia. Hoje, para a tecnologia, é muito fácil fazer uma criança. Então, se faz um filho e se dá para essa muIher que o pede. Na verdade, não é que haja mais mulheres inférteis e sim mais mulheres seduzidas 
pelo discurso da facilidade de ter um filho. Há mulheres que se dirigem às clínicas de reprodução porque não engravidam após três ou quatro meses de tentativas por meios naturais. [...] Tenho me perguntado se justamente esse discurso da facilidade não está fazendo com que os sintomas relacionados a ter um filho aumentem. (PINOS, 2003, p. 89).

Quiçá devêssemos justamente questionar essa "facilidade" mencionada nos tratamentos de reprodução assistida. Com todas as intervenções a que a muIher está sujeita, onde está a facilidade nisso? Conceber "naturalmente" não seria mais fácil? Além disso, devemos levar em conta os percentuais de sucesso das técnicas que ainda são muito baixos, normalmente da ordem de $25 \%$ ou $30 \%$ por tentativa, segundo Ramírez (2003a).

Para Rohden (2003), o que mais chama atenção nas pesquisas sobre NTRc são as permanências, especialmente as relacionadas às diferenças de gênero. Isso passa pela valorização da maternidade, que se traduz, de maneira singular, nas intervenções da ciência e da medicina, em particular.

$\mathrm{Na}$ verdade, estamos falando de um processo, no qual, o que está em jogo, a partir desse império da maternidade, é designar o que é da ordem do social ou do natural para as mulheres. No século XIX, isso era muito mais explícito nos textos médicos. Atualmente, embora o debate se complexifique com as novidades da ciência, é também preciso estranhar o imperativo da maternidade. Continua sendo muito recorrente na sociedade a ideia de que as mulheres têm que ser mães, de que é isso que as qualifica como mulheres, de que essa é sua missão no mundo (ROHDEN, 2003, p. 89 e 90).

No imaginário da sociedade contemporânea, ainda prevalece a perspectiva da mulher caracterizada por sua capacidade de procriar. Dessa perspectiva, parte a pressão social para que as mulheres tenham filhos, mesmo que à custa de uma intervenção médico-tecnológica (PINOS, 2003).

Para Oliveira (2002), a definição da maternidade como um fato natural é uma representação ideológica que proporciona uma imagem totalizadora e unificada de mulher-mãe. No entanto, ser mãe não é apenas um fato biológico, é também uma situação social e cultural. Neste sentido, existe uma construção social da maternidade.

As relações de gênero no contexto das NTRc ainda constituem relações de poder. Mesmo nos casos em que é comprovado que a esterilidade é masculina, as mulheres é que são medicamente tratadas, fato que, conforme Tamanini (2003), é apresentado como crítica na literatura feminista.

$E$, se no contexto das NTRc, ocorreu a entrada do homem no processo reprodutivo, as mulheres continuam a ser assimiladas como provedoras de gametas (TAMANINI, 2003). Embora sejam percebidas novas formas de maternidade e de paternidade, as concepções, historicamente legitimadas pela ciência, de que o 
óvulo é passivo e o espermatozoide ativo no processo reprodutivo ainda permanecem. É o que evidenciou Tamanini (2003), em seu estudo com médicos que trabalham com reprodução assistida.

Conforme Tamanini (p.159),

\begin{abstract}
O que é feito na ICSI como tratamento para a infertilidade masculina é tornar um homem pai, ainda que ele possua um único espermatozoide. Esse espermatozoide, se colocado no contexto de uma linguagem relacional de gênero ativo/passivo, continua sendo representado como aquele que é ativo. Uma vez injetado no núcleo do óvulo, recupera-se a linguagem da penetração via tecnologia. Parece sempre ser ele o potencializador do óvulo.
\end{abstract}

Se as relações entre os sexos ainda constituem relações de poder, no contexto da reprodução tecnológica, o poder médico também está muito presente. Para Ramírez (2003a), as NTRc estão inseridas em um contexto do mercado e transformam as mulheres em agentes passivos da habilitação médica.

\begin{abstract}
A divulgação de narrativas do desejo de filho biológico apresenta uma linguagem mercantilista, ofuscando a centralidade das mulheres na RA, que se tornaram agentes passivos de habilitação médico-tecnológica. A ressignificação de modelos de sexualidade e reprodução são reapropriados pela tecno-medicina, que os submete às suas regras e à lógica do capitalismo contemporâneo, transformando 'o que faz bater o coração mais rápido' em commodities ${ }^{4}$. (RAMÍREZ, 2003a, p. II, grifo da autora).
\end{abstract}

De acordo com Ramírez (2003a), por via da RA, haveria a promessa de um "avanço libertador para a mulher", no sentido de the conceder autonomia de escolhas reprodutivas, sem constrangimentos por causa da idade ou da ausência de um parceiro. A tecnologia permitiria às mulheres adiar a maternidade em razão de projetos profissionais, econômicos e pessoais. Esta questão, no entanto, será questionada, alguns anos depois, por uma pesquisa que discute o fenômeno social da "falta de filhos", resultante da postergação da maternidade e do baixo sucesso das NTRc em mulheres acima de 42 anos.

Se os avanços da contracepção contribuíram para separar a sexualidade da reprodução, dando maiores possibilidades às mulheres para conquistar autonomia social e econômica, as novas tecnologias reprodutivas conceptivas trouxeram consigo também o estigma da doença à infertilidade, conforme Scavone (2004, p. 96).

$4 \quad$ Define-se commodity como um produto passivel de padronização no que diz respeito à qualidade, quantidade e peso (MARQUES, 2005, p. 212). 
A apropriação da infertilidade familiar pela medicina tende a reeditar a norma do dever de procriar, já que a fertilidade artificial torna-se disponivel como mercadoria. As noções de infertilidade e de desejo de procriar passaram a ser normalizadas pela medicina.

Isso faz parecer que o acesso à maternidade tornou-se mais fácil com o desenvolvimento das NTRc. Para Rohden (2003), se existem tantas novas possibilidades de resolução de problemas relativos à fecundidade, todas as mulheres poderiam se tornar mães. Neste sentido, desejo e oferta da tecnologia estão diretamente relacionados. É também o que destaca a antropóloga Marilyn Strathern, de acordo com Rohden (2003):

\begin{abstract}
A antropóloga Marilyn Strathern chama a atenção para o fato de como, hoje, a capacidade de reproduzir passa por ter iniciativa e conseguir colocar esta iniciativa em prática. Isso implica consumir tecnologias que estão disponiveis. Neste sentido, parece que os indivíduos que não se reproduzem podem ser rotulados de incompetentes. "Somente quem não tem iniciativa ou poder aquisitivo não consegue consumir as novas alternativas disponiveis no mercado". (STRATHERN apud ROHDEN, 2003, p. 91, grifo nosso).
\end{abstract}

Estamos vivendo num tempo em que os indivíduos podem fazer escolhas, tudo é possivel. As ofertas do mercado preenchem qualquer lacuna. $O$ sêmen e o óvulo são transformados em objetos autônomos, em produtos. É o fetichismo do produto, o fetichismo do gene, como destaca Ramírez (2003a), dentro de uma lógica do capital e do mercado. Um tempo em que até as pessoas são tratadas como "objetos", como "commodities", como numa linha de produção. E o bebê que nasce de uma reprodução assistida é um "produto", uma commodity, "um produto passivel de padronização". E, entre os embriões obtidos em uma fertilização in vitro, só os "melhores" são escolhidos, os outros são descartados.

We are facing the expansion of a way of thinking that treats people as objects, as commodities. It is a way of thinking that enables us to see not motherhood, not parenthood, but the creation of a commodity, a baby. (ROTHMAN apud TAYLOR, 2004, p. 1).

Rocque (2004), em um texto que trata das "utopias e distopias feministas" no campo da ficção científica, aborda criticamente as Novas Tecnologias Reprodutivas conceptivas analisando a obra The handmaid's tale, da escritora canadense Margaret Atwood, que trata de um terrivel futuro no qual acontece um retrocesso tecnológico. Na república de Gilead, as mulheres são usadas como incubadoras 
humanas e a ausência de crianças é o maior problema.

\begin{abstract}
Embora a geração de crianças "imprestáveis" em Gilead seja altíssima e qualquer exame que detecte anomalias antes do parto seja totalmente proibido pelos fundamentalistas no poder, os bebês "de cabeça de alfinete ou focinho de cachorro" são eliminados, sub-repticiamente, ao nascerem. Podemos ver um paralelismo entre esses bebês "imprestáveis" em Gilead e os embriões congelados excedentes, ou também "imprestáveis" - nesse caso, detectados em nível cromossômico, com a mais fina flor da tecnologia - resultantes da técnica de fertilização in vitro [...]. (ROCQUE, 2004, p. 61, grifo da autora).
\end{abstract}

Ou ainda, podemos fazer uma analogia com os embriões que são descartados após a verificação de alguma anomalia genética por meio da técnica do diagnóstico genético de pré-implantação (DGPI).

As NTRc precisam ser situadas dentro do contexto do capitalismo e da modernidade, no qual qualquer "coisa" é passivel de consumo. Algumas autoras como Strathern (1992) e Taylor (2004) chegam a falar em uma cultura de consumo (consumer culture). Um conceito que está relacionado ao desejo das pessoas de terem uma criança, um filho biológico. A criança é a incorporação do desejo dos pais. Para Strathern (1992), a ideia de parentesco nas NTRc está baseada na ideia de escolha e, esta, por sua vez, está baseada na ideia de consumo. "A escolha cria o consumo como um ato subjetivo" (STRATHERN, 1992, p. 134).

E essa escolha engloba não somente a decisão por ter um filho, mas as possibilidades de determinar o sexo e outras características genéticas, já que, de acordo com Strathern (1992), o advento das NTRc significa deter o controle da nossa própria biologia e do nosso próprio processo reprodutivo.

No caso do Brasil, essa escolha é questionável, já que é preciso levar em conta as desigualdades sociais e a assistência à saúde reprodutiva das mulheres. Não temos dúvida de que as NTRc constituem uma possibilidade de autonomia para as mulheres, principalmente àquelas de maior escolaridade e renda, que muitas vezes adiam seu projeto de maternidade em razão de outros projetos pessoais e profissionais. Contudo, devemos considerar a falta de atenção à saúde no país, do que decorre o número exorbitante de abortos clandestinos, esterilizações cirúrgicas, gravidez na adolescência, desconhecimento sobre o uso dos métodos contraceptivos etc., fatos estes que podem levar, sobretudo no caso das mulheres de baixa escolaridade e renda, à procura das NTRc. $O$ que nos leva a pensar, como Barbosa (2000), na existência de classes distintas de mulheres no Brasil em se tratando do uso e do acesso às NTRc. Devemos levar em conta também os riscos para a saúde das mulheres e as reais possibilidades de sucesso dessas tecnologias, muitas vezes não mencionadas pelos médicos. 
Todas essas questões nos levam a reiterar junto com Scavone (2004) a importância de uma reflexão permanente e da ampliação do debate público sobre o desenvolvimento destas tecnologias, suas condições de uso, suas implicações subjetivas, sociais e éticas, buscando fornecer elementos para tornar exequivel a noção de cidadania reprodutiva.

\section{Referências}

ÁVILA, Maria Betânia. Modernidade e cidadania reprodutiva. Estudos Feministas, Rio de Janeiro, n. 2, pp. 382-393, 1993.

BARBOSA, Rosana Machin. Novas tecnologias reprodutivas conceptivas: produzindo classes distintas de mulheres? In: GROSSI, Miriam; PORTO, Rozeli;

TAMANINI, Marlene (Org.). Novas Tecnologias Reprodutivas Conceptivas: Questões e desafios. Brasillia: Letras Livres, 2000.

CORRÊA, Marilena. Novas tecnologias reprodutivas: bem-vindas reflexões feministas. Estudos Feministas, Rio de Janeiro, n. 6, pp. 126-137, 1998.

COSTA, Rosely Gomes. Tecnologias reprodutivas e atribuições de paternidade e maternidade. In: GROSSI, Miriam; PORTO, Rozeli; TAMANINI, Marlene (Org.). Novas Tecnologias Reprodutivas Conceptivas: Questões e desafios. Brasillia: Letras Livres, 2003.

LABORIE, Françoise. Novas tecnologias da reprodução: risco ou liberdade para as mulheres? Estudos Feministas, Rio de Janeiro, n. 2, pp. 435-447, 1993.

MARQUES, Pedro Valentim. Mercados futuros e de opções agropecuários. In: ZYLBERSZTAJN, Decio \& NEVES, Marcos Fava (Org.). Economia e gestão dos negócios agroalimentares. São Paulo: Pioneira Thompson Learning, 2005.

OLIVEIRA, Fátima. Um olhar feminista sobre biotecnologia. Jornal da Rede Feminista de Saúde. Belo Horizonte: Rede Nacional Feminista de Saúde, Direitos Sexuais e Direitos Reprodutivos, n. 25, 2002.

PINOS, Amanda. Mães, ainda. In: GROSSI, Miriam; PORTO, Rozeli; TAMANINI, Marlene (Org.). Novas Tecnologias Reprodutivas Conceptivas: Questões e desafios. Brasilia, Letras Livres, 2003.

RAMÍREZ, Martha Celia. Novas tecnologias reprodutivas conceptivas: fabricando a vida, fabricando o futuro. 2003 Tese (Doutorado em Ciências Sociais) - Universidade Estadual de Campinas, Campinas, 2003a.

Questões e desafios decorrentes da fabricação de bebês. In: GROSSI, 
Miriam; PORTO, Rozeli; TAMANINI, Marlene (Org.). Novas Tecnologias Reprodutivas Conceptivas: Questões e desafios. Brasilia: Letras Livres, $2003 \mathrm{~b}$.

ROCQUE, Lucia de la. Gênero e reprodução em questão: utopias e distopias feministas. In: JORGE, Tânia C. de Araújo (Org.). Ciência e Arte: encontros e sintonias. Rio de Janeiro: Senac Rio, 2004.

ROHDEN, Fabíola. Debate - Parte I. In: GROSSI, Miriam; PORTO, Rozeli; TAMANINI, Marlene (Org.). Novas Tecnologias Reprodutivas Conceptivas: Questões e desafios. Brasilia, Letras Livres, 2003.

ROTANIA, Alejandra. A celebração do temor: biotecnologias, reprodução, ética e feminismo. Rio de Janeiro: E-papers Serviços Editoriais, 2001.

SCAVONE, Lucila. Dar a vida e cuidar da vida: Feminismo e Ciências Sociais. São Paulo - SP, Editora UNESP, 2004.

SCOTT, Joan. Gênero: uma categoria útil de análise histórica. Educação e Realidade, Porto Alegre, n. 20, pp. 71-99, 1995.

STRATHERN, Marilyn. Reproducing the future: anthropology, kinship and new reproductive technologies. New York: Routledge, 1992.

STOLCKE, Verena. El sexo de la biotecnología. Estudos Feministas, Rio de Janeiro, n. 6, pp. 139-155, 1998.

TAIN, Laurence. Um filho quando eu quiser: o caso da França contemporânea. Estudos Feministas, Florianópolis, n. 1, p. 53-67, 2005.

TAMANINI, Marlene. Novas tecnologias reprodutivas conceptivas à luz da Bioética e das teorias de gênero: casais e médic@s no sul do Brasil. 2003. Tese (Doutorado Interdisciplinar em Ciências Humanas) - Universidade Federal de Santa Catarina, Florianópolis, 2003.

TAYLOR, Janelle S. Introduction. In: TAYLOR, Janelle S.; LAYNE, Linda; WOZNIAK, Danielle F. (Org.) Consuming motherhood. New Bruswick: Rutgers University Press, 2004.

Recebido em agosto de 2018.

Aprovado em dezembro de 2018. 